\title{
Factors Associated with Radiation Toxicity and Survival in Patients with Presumed Early- Stage Non-Small Cell Lung Cancer Receiving Empiric Stereotactic Ablative Radiotherapy
}

\author{
John Park, MD; Curtis Whiting, MD; Eashwer Reddy, MD; Sushant Govindan, MD; Chao Huang, MD; and Sonia M. Castillo, MD
}

Objectives: Stereotactic ablative radiotherapy (SABR) has become the standard of care for inoperable early-stage nonsmall cell lung cancer (NSCLC). Many patients cannot safely undergo a biopsy because of poor pulmonary function and are empirically treated with radiotherapy. This study aimed to evaluate factors associated with radiation toxicity in patients receiving empiric SABR.

Methods: We performed a retrospective review of 69 patients. Patients and tumor characteristics, radiation doses, pulmonary function tests, and toxicity (acute $\leq 90$ days and late $>90$ days) were analyzed to find associations with overall survival on Kaplan-Meier curves and differences in patient populations with $\chi^{2}$ and Mann-Whitney $U$ tests.

Results: Median age was 71 years. Tumors were classified as peripheral in 62 patients $(89.9 \%)$. After a median followup of 18 months, 39 patients $(56.5 \%)$ were alive with 4 local recurrences (5.7\%), 10 regional failures (14.3\%), and 15 distant metastases (21.4\%). Nineteen of 67 (26.3\%) patients had acute toxicity of which 9 had acute grade $\geq 2$ toxicity. There were differences in overall survival based on operability status $(P=.031)$ and acute toxicity $(P<.001)$. Pretreatment oxygen dependence $(P=.003)$, central location $(P<.001)$, and new oxygen requirement $(P=.02)$ were significantly associated with acute grade $\geq 2$ toxicity. No association was found with performance on pulmonary function tests.

Conclusion: Empiric SABR in presumed early-stage NSCLC appears to be safe and may increase overall survival. Acute grade $\geq 2$ toxicity was significantly associated with pretreatment oxygen dependence, central location, and new oxygen requirement. No association was found with poor pulmonary function.
Author affiliations can be found at the end of the article. Corrrespondence: John Park (john.park@va.gov)

Fed Pract. 2021;38(suppl 2) Published online May 10 doi:10.12788/fp.0129
$\mathrm{S}$ tereotactic ablative radiotherapy (SABR) has become the standard of care for inoperable early-stage non-small cell lung cancer (NSCLC). Many patients are unable to undergo a biopsy safely because of poor pulmonary function or underlying emphysema and are then empirically treated with radiotherapy if they meet criteria. In these patients, local control can be achieved with SABR with minimal toxicity. ${ }^{1}$ Considering that median overall survival (OS) among patients with untreated stage I NSCLC has been reported to be as low as 9 months, early treatment with SABR could lead to increased survival of 29 to 60 months. ${ }^{2-4}$

The RTOG 0236 trial showed a median OS of 48 months and the randomized phase III CHISEL trial showed a median OS of 60 months; however, these survival data were reported in patients who were able to safely undergo a biopsy and had confirmed NSCLC. ${ }^{4,5}$ For patients without a diagnosis confirmed by biopsy and who are treated with empiric SABR, patient factors that influence radiation toxicity and $O S$ are not well defined.

It is not clear if empiric radiation benefits survival or if treatment causes decline in lung func- tion, considering that underlying chronic lung disease precludes these patients from biopsy. The purpose of this study was to evaluate the factors associated with radiation toxicity with empiric SABR and to evaluate OS in this population without a biopsy-confirmed diagnosis.

\section{METHODS}

This was a single center retrospective review of patients treated at the radiation oncology department at the Kansas City Veterans Affairs Medical Center from August 2014 to February 2019. Data were collected on 69 patients with pulmonary nodules identified by chest computed tomography (CT) and/or positron emission tomography (PET)-CT that were highly suspicious for primary NSCLC.

These patients were presented at a multidisciplinary meeting that involved pulmonologists, oncologists, radiation oncologists, and thoracic surgeons. Patients were deemed to be poor candidates for biopsy because of severe underlying emphysema, which would put them at high risk for pneumothorax with a percutaneous needle biopsy, or were unable to tolerate general anesthesia for navigational bronchoscopy or surgical biopsy because of poor lung 
TABLE 1 Common Terminology Criteria for Adverse Events Scale

\begin{tabular}{|c|c|c|c|c|c|}
\hline Symptoms & Grade 1 & Grade 2 & Grade 3 & Grade 4 & Grade 5 \\
\hline Dyspnea & $\begin{array}{l}\text { Shortness of breath } \\
\text { with moderate exertion }\end{array}$ & $\begin{array}{l}\text { Shortness of breath with } \\
\text { minimal exertion; limiting } \\
\text { instrumental ADLs }\end{array}$ & $\begin{array}{l}\text { Shortness of breath } \\
\text { at rest; limiting } \\
\text { self-care ADLs }\end{array}$ & $\begin{array}{l}\text { Life-threatening } \\
\text { consequences; urgent } \\
\text { intervention indicated }\end{array}$ & Death \\
\hline Cough & $\begin{array}{l}\text { Mild symptoms; } \\
\text { nonprescription } \\
\text { intervention indicated }\end{array}$ & $\begin{array}{l}\text { Moderate symptoms, medical } \\
\text { intervention indicated; limiting } \\
\text { instrumental ADLs }\end{array}$ & $\begin{array}{l}\text { Severe symptoms; } \\
\text { limiting self-care } \\
\text { ADLs }\end{array}$ & - & - \\
\hline $\begin{array}{l}\text { Chest wall } \\
\text { pain }\end{array}$ & Mild pain & $\begin{array}{l}\text { Moderate pain; limiting } \\
\text { instrumental ADLs }\end{array}$ & $\begin{array}{l}\text { Severe pain; limiting } \\
\text { self-care ADLs }\end{array}$ & - & - \\
\hline $\begin{array}{l}\text { Esophageal } \\
\text { pain }\end{array}$ & Mild pain & $\begin{array}{l}\text { Moderate pain; limiting } \\
\text { instrumental ADLs }\end{array}$ & $\begin{array}{l}\text { Severe pain; limiting } \\
\text { self-care ADLs }\end{array}$ & - & - \\
\hline
\end{tabular}

Abbreviation: ADL, activities of daily living.

function. These patients were diagnosed with presumed stage I NSCLC using the criteria: minimum of 2 sequential CT scans with enlarging nodule; absence of metastases on PET-CT; the single nodule had to be fluorodeoxyglucose avid with a minimum standardized uptake value of 2.5, and absence of clinical history or physical examination consistent with small cell lung cancer or infection.

After a consensus was reached that patients met these criteria, individuals were referred for empiric SABR. Follow-up visits were at 1 month, 3 months, and every 6 months. Variables analyzed included: patient demographics, pre- and posttreatment pulmonary function tests (PFT) when available, pre-treatment oxygen use, tumor size and location (peripheral, central, or ultracentral), radiation doses, and grade of toxicity as defined by Human and Health Services Common Terminology Criteria for Adverse Events version 5.0 (dyspnea and cough both counted as pulmonary toxicity): acute $\leq 90$ days and late $>90$ days (Table 1).

SPSS versions 24 and 26 were used for statistical analysis. Median and range were obtained for continuous variables with a normal distribution. Kaplan-Meier log-rank testing was used to analyze OS. $\chi^{2}$ and Mann-Whitney $U$ tests were used to analyze association between independent variables and OS. Analysis of significant findings were repeated with operable patients excluded for further analysis.

\section{RESULTS}

The median follow-up was 18 months (range, 1 to 54 ). The median age was 71 years (range, 59 to 95 ) (Table 2). Most patients $(97.1 \%)$ were male. The majority of patients $(79.4 \%)$ had a
0 or 1 for the Eastern Cooperative Oncology group performance status, indicating fully active or restricted in physically strenuous activity but ambulatory and able to perform light work. All patients were either current or former smokers with an average pack-year history of 69.4. Only $11.6 \%$ of patients had operable disease, but received empiric SABR because they declined surgery. Four patients did not have pretreatment spirometry available and 37 did not have pretreatment diffusing capacity for carbon monoxide (DLCO) data.

Most patients had a pretreatment forced expiratory volume during the first seconds $\left(\mathrm{FEV}_{1}\right)$ value and DLCO $<60 \%$ of predicted $(60 \%$ and $84 \%$ of the patients, respectively). The median tumor diameter was $2 \mathrm{~cm}$. Of the $68.2 \%$ of patients who did not have chronic hypoxemic respiratory failure before SABR, 16\% developed a new requirement for supplemental oxygen. Sixtytwo tumors $(89.9 \%)$ were peripheral. There were 4 local recurrences $(5.7 \%), 10$ regional (different lobe and nodal) failures (14.3\%), and 15 distant metastases (21.4\%).

Nineteen of 67 patients (26.3\%) had acute toxicity of which 9 had acute grade $\geq 2$ toxicity; information regarding toxicity was missing on 2 patients. Thirty-two of $65(49.9 \%)$ patients had late toxicity of which $20(30.8 \%)$ had late grade $\geq 2$ toxicity. The main factor associated with development of acute toxicity was pretreatment oxygen dependence $(P=.047)$. This was not significant when comparing only inoperable patients. Twenty patients (29.9\%) developed some type of acute toxicity; pulmonary toxicity was most common (22.4\%) (Table 3). All patients with acute toxicity also developed late toxicity except for 1 who died before 3 months. 
TABLE 2 Baseline Characteristics of Patients Undergoing Empiric Stereotactic Ablative Radiotherapy

\begin{tabular}{|c|c|}
\hline Characteristics & Results \\
\hline Age, median (range), y & $71(59-95)$ \\
\hline Male, \% & 97.1 \\
\hline \multicolumn{2}{|l|}{ Performance status, \% } \\
\hline 0 & 38.2 \\
\hline 1 & 41.2 \\
\hline 2 & 17.6 \\
\hline 3 & 3.0 \\
\hline \multicolumn{2}{|l|}{ Smoking status, \% } \\
\hline Current & 43.5 \\
\hline Former & 56.5 \\
\hline Pack-years, mean (SD) & $69.4(32.2)$ \\
\hline Operable tumor, \% & 11.6 \\
\hline \multicolumn{2}{|l|}{ Prior $\mathrm{FEV}_{1}$ predicted, $\%$} \\
\hline$>60 \%$ & 40.0 \\
\hline $\begin{array}{l}30 \text { to } 60 \% \\
<30 \%\end{array}$ & $\begin{array}{l}49.2 \\
10.8\end{array}$ \\
\hline \multicolumn{2}{|l|}{ Prior DLCO percentage predicted, } \\
\hline $\begin{array}{l}\% \\
>60 \%\end{array}$ & $\begin{array}{l}15.6 \% \\
71.9 \%\end{array}$ \\
\hline 30 to $60 \%$ & $12.5 \%$ \\
\hline$<30 \%$ & \\
\hline Tumor diameter, median (range), cm & $2.0(0.9-5.6)$ \\
\hline \multicolumn{2}{|l|}{ Location, \% } \\
\hline Peripheral & 89.9 \\
\hline Central & 10.1 \\
\hline Prior oxygen dependence, $\%$ & 31.8 \\
\hline New oxygen requirement, $\%$ & 16 \\
\hline
\end{tabular}

Abbreviations: DLCO, diffusing capacity for carbon monoxide; $\mathrm{FEV}_{1}$, forced expiratory volume during the first seconds.

Predominantly, the deaths in our sample were from causes other than the malignancy or treatment, such as sepsis, deconditioning after a fall, cardiovascular complications, etc. Acute toxicity of grade $\geq 2$ was significantly associated with late toxicity $(P<.001$ for both) in both operable and inoperable patients $(P<.001)$.

Development of any acute toxicity grade $\geq 2$ was significantly associated with oxygen dependence at baseline $(P=.003)$, central location $(P<.001)$, and new oxygen requirement $(P=.02)$. Only central tumor location was found to be significant $(P=.001)$ within the inoperable cohort. There were no significant differences in outcome based on pulmonary function testing ( $\mathrm{FEV}_{1}$, forced vital capacity, or DLCO) or the ana-
TABLE 3 Acute Toxicities ( $\mathrm{n}=67$ )

\begin{tabular}{lc} 
Toxicities & Patients, No. (\%) \\
\hline Pulmonary & $15(22.4)$ \\
\hline Chest wall & $5(7.5)$ \\
\hline Esophageal & $1(1.5)$ \\
\hline Total & $20(29.9)$
\end{tabular}

lyzed PFT subgroups $\left(\mathrm{FEV}_{1}<1.0 \mathrm{~L}, \mathrm{FEV}_{1}<1.5 \mathrm{~L}\right.$, $\mathrm{FEV}_{1}<30 \%$, and $\mathrm{FEV}_{1}<35 \%$ ).

At the time of data collection, 30 patients were deceased $(43.5 \%)$. There was a statistically significant association between OS and operability $(P=.03$; Table 4 , Figure 1$)$. Decreased OS was significantly associated with acute toxicity $(P=.001)$ and acute toxicity grade $\geq 2(P=.005$; Figures 2 and 3$)$. For the inoperable patients, both acute toxicity $(P<.001)$ and acute toxicity grade $\geq 2(P=$ .026) remained significant.

\section{DISCUSSION}

SABR is an effective treatment for inoperable early-stage NSCLC, however its therapeutic ratio in a more frail population who cannot withstand biopsy is not well established. Additionally, the prevalence of benign disease in patients with solitary pulmonary nodules can be between $9 \%$ and $21 \% .{ }^{6}$ Haidar and colleagues looked at 55 patients who received empiric SABR and found a median OS of 30.2 months with an $8.7 \%$ risk of local failure, $13 \%$ risk of regional failure with $8.7 \%$ acute toxicity, and $13 \%$ chronic toxicity. ${ }^{7}$ Data from Harkenrider and colleagues $(n=34)$ revealed similar results with a 2 -year OS of $85 \%$, local control of $97.1 \%$, and regional control of $80 \%$. The authors noted no grade $\geq 3$ acute toxicities and an incidence of grade $\geq 3$ late toxicities of $8.8 \% .^{1}$ These findings are concordant with our study results, confirming the safety and efficacy of SABR. Furthermore, a National Cancer Database analysis of observation vs empiric SABR found an OS of 10.1 months and 29 months respectively, with a hazard ratio of $0.64(P<.001) .{ }^{3}$ Additionally, Fischer-Valuck and colleagues $(n=88) \mathrm{com}$ pared biopsy confirmed vs unbiopsied patients treated with SABR and found no difference in the 3-year local progression-free survival $(93.1 \%$ vs $94.1 \%)$, regional lymph node metastasis and distant metastases free survival $(92.5 \%$ 
TABLE 4 Variables Associated with Overall Survival

\begin{tabular}{lcc} 
Variables & Patients alive, No. (\%) & $P$ value \\
\hline $\begin{array}{l}\text { Survival status } \\
(n=69)\end{array}$ & $39(56.5)$ & N/A \\
\hline $\begin{array}{l}\text { Acute toxicity } \\
(n=19)\end{array}$ & $5(48.7)$ & $<.001$ \\
\hline $\begin{array}{l}\text { Acute toxicity } \\
\text { grade } \geq 2(n=9)\end{array}$ & $1(11.1)$ & .005 \\
\hline Operable $(n=8)$ & $7(87.5)$ & .03
\end{tabular}

vs $87.4 \%)$, or OS $(59.9 \%$ vs $58.9 \%) .{ }^{8}$ With a median OS of $\leq 1$ year for untreated stage I NSCLC, these studies support treating patients with empiric SABR. ${ }^{4}$

Other researchers have sought parameters to identify patients for whom radiation therapy would be too toxic. Guckenberger and colleagues aimed to establish a lower limit of pretreatment PFT to exclude patients and found only a $7 \%$ incidence of grade $\geq 2$ adverse effects and toxicity did not increase with lower pulmonary function. ${ }^{9}$ They concluded that SABR was safe even for patients with poor pulmonary function. Other institutions have confirmed such findings and have been unable to find a cut-off PFT to exclude patients from empiric SABR. ${ }^{10,11}$ An analysis from the RTOG 0236 trial also noted that poor baseline PFT could not predict pulmonary toxicity or survival. Additionally, the study demonstrated only minimal decreases in patients' FEV $_{1}(5.8 \%)$ and DLCO (6\%) at 2 years. ${ }^{12}$

Our study sought to identify a cut-off on FEV $_{1}$ or DLCO that could be associated with increased toxicity. We also evaluated the incidence of acute toxicities grade $\geq 2$ by stratifying patients according to $\mathrm{FEV}_{1}$ into subgroups: $\mathrm{FEV}_{1}<1.0 \mathrm{~L} \mathrm{FEV}_{1}<1.5 \mathrm{~L}, \mathrm{FEV}_{1}<30 \%$ of predicted and $\mathrm{FEV}_{1}<35 \%$ of predicted. However, similar to other studies, we did not find any value that was significantly associated with increased toxicity that could preclude empiric SABR. One possible reason is that no treatment is offered for patients with extremely poor lung function as deemed by clinical judgement, therefore data on these patients is unavailable. In contradiction to other studies, our study found that oxygen dependence before treatment was significantly
FIGURE 1 Operability

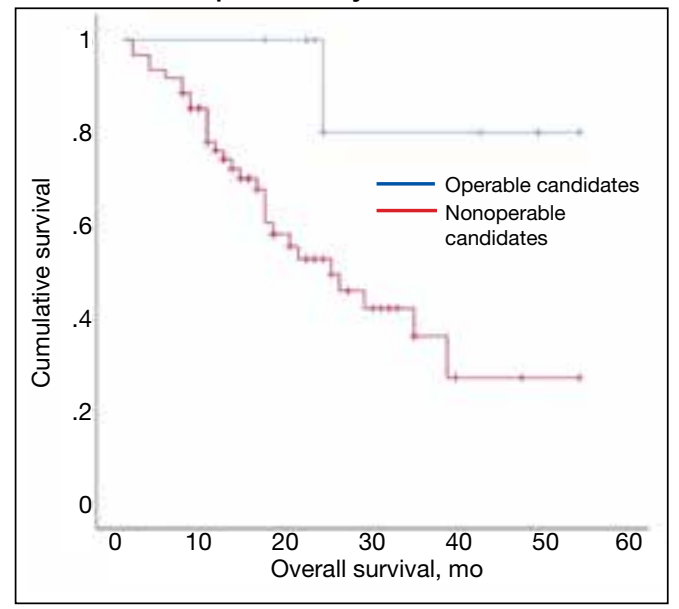

FIGURE 2 Acute Toxicity

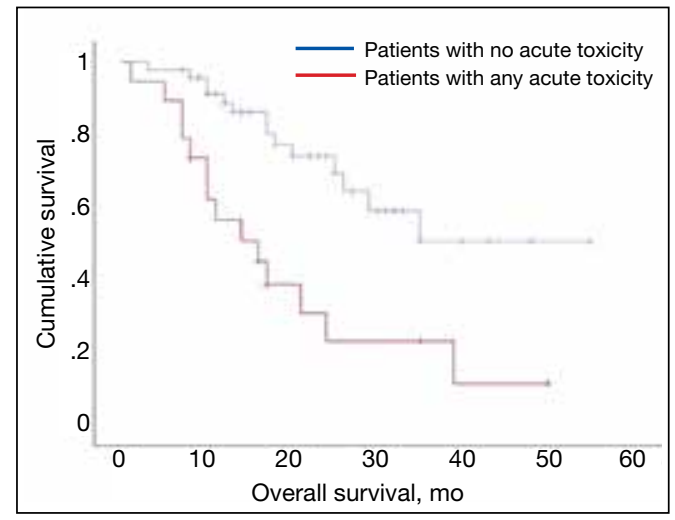

FIGURE 3 Acute Toxicity $\geq 2$ Grade

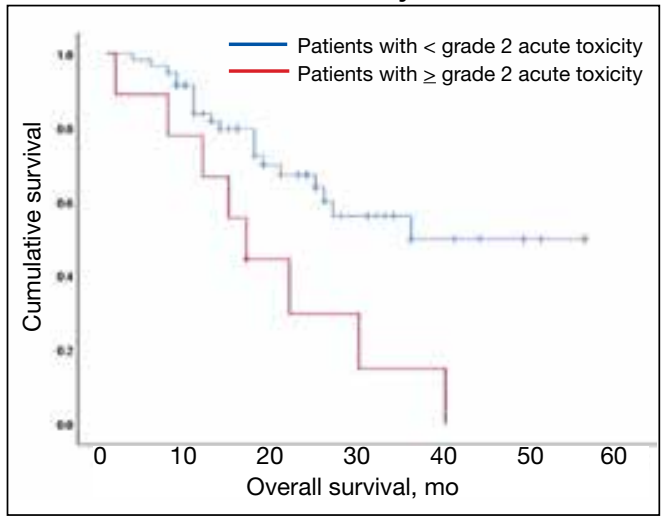

associated with development of acute toxicities. The exact mechanism for this association is unknown and could not be elucidated by baseline PFT. One possible explanation is that SABR could lead to oxygen free radical generation. In addition, our study indicated that those who developed acute toxicities had worse OS. 


\section{Limitations}

Our study is limited by caveats of a retrospective study and its small sample size, but is in line with the reported literature (ranging from 33 to 88 patients). ${ }^{1,7,8}$ Another limitation is that data on pretreatment DLCO was missing in 37 patients and the lack of statistical robustness in terms of the smaller inoperable cohort, which limits the analyses of these factors in regards to anticipated morbidity from SABR. Also, given this is data collected from the US Department of Veterans Affairs, only $3 \%$ of our sample was female.

\section{CONCLUSIONS}

Empiric SABR for patients with presumed earlystage NSCLC appears to be safe and might positively impact OS. Development of any acute toxicity grade $\geq 2$ was significantly associated with dependence on supplemental oxygen before treatment, central tumor location, and development of new oxygen requirement. No association was found in patients with poor pulmonary function before treatment because we could not find a FEV 1 or DLCO cutoff that could preclude patients from empiric SABR. Considering the poor survival of untreated early-stage NSCLC, coupled with the efficacy and safety of empiric SABR for those with presumed disease, definitive SABR should be offered selectively within this patient population.

\section{Author affiliations}

John Park is a Radiation Oncologist; Eashwer Reddy is the Section Chief of Radiation Oncology; Sushant Govindan is a Pulmonology and Critical Care Physician; Chao Huang is the Section Chief of Hematology/Medical Oncology; and Sonia Castillo is a Pulmonology and Critical Care Physician, all at the Kansas City VA Medical Center in Missouri. Curtis Whiting is a Pulmonology and Critical Care Physician at Our Lady of the Lake Regional Medical Center in Baton Rouge, Louisiana. John Park is a clinical Assistant Professor and Eashwer Reddy is a Clincal Professor at the University of Missouri in Kansas City. Sushant Govindan is an Assistant Professor, Chao Huang is a Professor, and Sonia Castillo is a Clinical Assistant Professor, all at University of Kansas Medical Center in Kansas City, Kansas.

\section{Acknowledgments}

Drs. Park, Whiting and Castillo contributed to data collection. Drs. Park, Govindan and Castillo contributed to the statistical analysis and writing the first draft and final manuscript. Drs. Park, Govindan, Huang, and Reddy contributed to the discussion section.

\section{Author disclosures}

The authors report no actual or potential conflicts of interest with regard to this article.

\section{Disclaimer}

The opinions expressed herein are those of the authors and do not necessarily reflect those of Federal Practitioner, Frontline Medical Communications Inc., the US Government, or any of its agencies.

\section{References}

1. Harkenrider MM, Bertke MH, Dunlap NE. Stereotactic body radiation therapy for unbiopsied early-stage lung cancer: a multi-institutional analysis. Am J Clin Oncol. 2014;37(4):337-342. doi:10.1097/COC.0b013e318277d822

2. Raz DJ, Zell JA, Ou SH, Gandara DR, Anton-Culver H, Jablons DM. Natural history of stage I non-small cell lung cancer: implications for early detection. Chest. 2007;132(1):193-199. doi:10.1378/chest.06-3096

3. Nanda RH, Liu Y, Gillespie TW, et al. Stereotactic body radiation therapy versus no treatment for early stage non-small cell lung cancer in medically inoperable elderly patients: a National Cancer Data Base analysis. Cancer. 2015;121(23):4222-4230. doi:10.1002/cncr.29640

4. Ball D, Mai GT, Vinod S, et al. Stereotactic ablative radiotherapy versus standard radiotherapy in stage 1 non-small-cell lung cancer (TROG 09.02 CHISEL): a phase 3 , open-label, randomised controlled trial. Lancet Oncol. 2019;20(4):494-503. doi:10.1016/S1470-2045(18)30896-9

5. Timmerman R, Paulus R, Galvin J, et al. Stereotactic body radiation therapy for inoperable early stage lung cancer. JAMA. 2010;303(11):1070-1076. doi:10.1001/jama.2010.261

6. Smith MA, Battafarano RJ, Meyers BF, Zoole JB, Cooper JD, Patterson GA. Prevalence of benign disease in patients undergoing resection for suspected lung cancer. Ann Thorac Surg. 2006;81(5):1824-1828. doi:10.1016/j.athoracsur.2005.11.010

7. Haidar YM, Rahn DA 3rd, Nath S, et al. Comparison of outcomes following stereotactic body radiotherapy for nonsmall cell lung cancer in patients with and without pathological confirmation. Ther Adv Respir Dis. 2014;8(1):3-12. doi:10.1177/1753465813512545

8. Fischer-Valuck BW, Boggs H, Katz S, Durci M, Acharya S, Rosen LR. Comparison of stereotactic body radiation therapy for biopsy-proven versus radiographically diagnosed early-stage non-small lung cancer: a singleinstitution experience. Tumori. 2015;101(3):287-293. doi:10.5301/tj.5000279

9. Guckenberger M, Kestin LL, Hope AJ, et al. Is there a lower limit of pretreatment pulmonary function for safe and effective stereotactic body radiotherapy for early-stage non-small cell lung cancer? J Thorac Oncol. 2012;7:542551. doi:10.1097/JTO.0b013e31824165d7

10. Wang J, Cao J, Yuan S, et al. Poor baseline pulmonary function may not increase the risk of radiation-induced lung toxicity. Int J Radiat Oncol Biol Phys. 2013;85(3):798804. doi:10.1016/j.jirobp.2012.06.040

11. Henderson M, McGarry R, Yiannoutsos C, et al. Baseline pulmonary function as a predictor for survival and decline in pulmonary function over time in patients undergoing stereotactic body radiotherapy for the treatment of stage I non-small-cell lung cancer. Int J Radiat Oncol Biol Phys. 2008;72(2):404-409. doi:10.1016/j.jijobp.2007.12.051

12. Stanic $S$, Paulus $R$, Timmerman $R D$, et al. No clinically significant changes in pulmonary function following stereotactic body radiation therapy for early- stage peripheral non-small cell lung cancer: an analysis of RTOG 0236. Int J Radiat Oncol Biol Phys. 2014;88(5):1092-1099. doi:10.1016/j.jirobp.2013.12.050 